\title{
A Case of Dermatomyositis: Diagnostic Challenge in Low Resource Settings
}

\author{
Richmond Ronald Gomes ${ }^{1^{*}}$ \\ ${ }^{1}$ Associate Professor, Medicine, \\ Ad-din Women's Medical College \\ Hospital, Dhaka \\ ${ }^{2}$ Assistant Professor, Nephrology, \\ Ad-din Women's Medical College \\ Hospital, Dhaka
}

\author{
Dr. Saiful Bahar Khan ${ }^{2}$
}

\begin{abstract}
Dermatomyositis is one of the idiopathic inflammatory myopathies. It is characterized clinically by progressive symmetrical proximal muscle weakness and a characteristic rash. Although the process primarily attacks the skin and the muscles, it is a systemic disease with frequent manifestations in the gastrointestinal tract and pulmonary system. Dermatomyositis has been linked to internal malignancy in somewhere between $15 \%$ and $25 \%$. We report a case involving a 30 years old female nurse who presented with extensive erythema involving face and upper neck, and deteriorating proximal muscular weakness for three months. Later muscle enzymes, EMG and biopsy were done from BSMMU, Dhaka, confirmed the diagnosis of Dermatomyositis. Oral prednisolone along with azathioprine, hydroxychloroquine and photo protection with sun screen were started and showed good response both clinically and biochemically.

Keywords: Dermatomyositis, heliotrope rash, gottron's papules
\end{abstract}

\section{1 | INTRODUCTION:}

$\mathrm{D}$ ermatomyositis (DM) is one of the idiopathic inflammatory myopathies. ${ }^{1-3}$ It has two peaks of occurrence, one in childhood and one between the age of 45 and 65 years $^{10-11}$. The estimated annual incidence rates ranged from 2 to 10 cases per million. ${ }^{12}$ In 1975 , Bohan and Peter ${ }^{4}$ published a classic article that suggested a set of criteria to aid in the diagnosis and classification of $\mathrm{DM}$ and polymyositis (PM). Of the 5 criteria, 4 related to the muscle disease: (1) progressive proximal symmetrical weakness, (2) elevated muscles enzymes, (3) an abnormal electromyogram, and (4) an abnormal muscle biopsy, while the fifth was the presence of compatible cutaneous disease. It was felt that DM differed from PM only by the presence of cutaneous disease. Recent studies of the pathogenesis of the myopathy have been controversial, some suggesting that the myopathies in DM and PM are pathogenetically different with DM being due to a vascular inflammation, ${ }^{5}$ whereas other studies of cytokines suggest that the processes are similar. ${ }^{6-9}$ There has been a renewed interest in the pathogenic mechanisms involved in the myopathy with recent

Supplementary information The online version of this article (https://doi.org/10.15520/mcrr.v3i7.119) contains supplementary material, which is available to authorized users.

Corresponding Author: Richmond Ronald Gomes Associate Professor, Medicine, Ad-din Women's Medical College Hospital, Dhaka 
studies revealing abnormal levels of nitric oxide, elevation of circulating tumor necrosis factor (TNF) receptors, elevated soluble CD40 expression, and increased expression of major histo compatibility complex class I and interleukin 1a within the muscle. The pathogenesis of the cutaneous disease is poorly understood.

\section{2 | CASE PRESENTATION:}

On $15^{\text {th }}$ January 2019, a 30 years old fair female married nurse presented to the Department of Internal Medicine, Ad-din Sakina Medical College \& Hospital, Jessore, Bangladesh with the complaints of extensive photo sensitive erythema involving face, neck, upper chest; alopecia and deteriorating proximal muscular weakness for three months. But patient denied any joint pain, oral ulcer, history of abortion, haematuria, features supporting raynaud's phenomenon, any respiratory and gastrointestinal complaints. On examination there was wide spread violaceous erythema involving face, "V" of neck and upper back (shawl sign). There were some poikilodermic changes (atrophy, hypopigmentation, talangiectesia) over upper aspect of the back with focal alopecia. Some periorbital oedema was also noted with heliotrope rash. But gottron's papules, hyperkeratosis of hands (mechanical hands), periungual talangiectesia and holsters sign (poikiloderma of upper lateral thigh) were absent. Neurological examination revealed reduced proximal muscle strength $(3+/ 5)$ in both upper and lower limb compared to distal power $(5 / 5)$. No other focal neurological signs were elicited. Cardiovascular, respiratory and abdominal examinations were unremarkable.

Baseline haematological and biochemical investigations revealed normal complete blood count, $\mathrm{Hb} \%-12.4$ gm/dl, WBC-7600/cc, Neutrophil-50\%, Lymphocyte-42\%, Eosinophil-4\%, total platelet count 393000/cc. Inflammatory markers were elevated with ESR-42mm in Ist hour and CRP 45. LDH, AST, levels were elevated at 2290U/L and 243U/L respectively. Her CPK level was significantly raised with 13738/L (Normal: 30135U/L). ANA, Anti ds DNA, Rheumatoid factor, ENA profile, HBsAg were negative. EMG findings

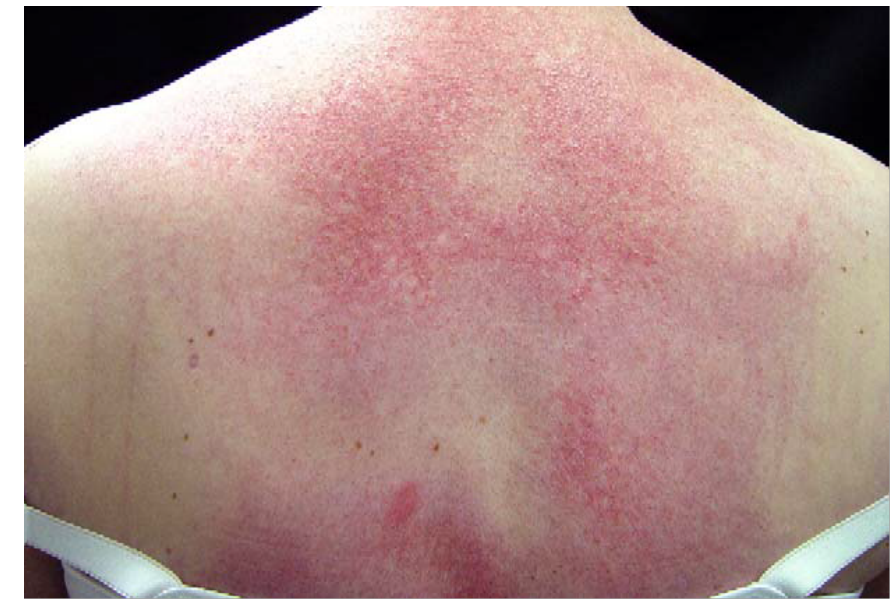

FIGURE 1: Poikiloderma on the upper aspect of back is typical of the shawl sign.

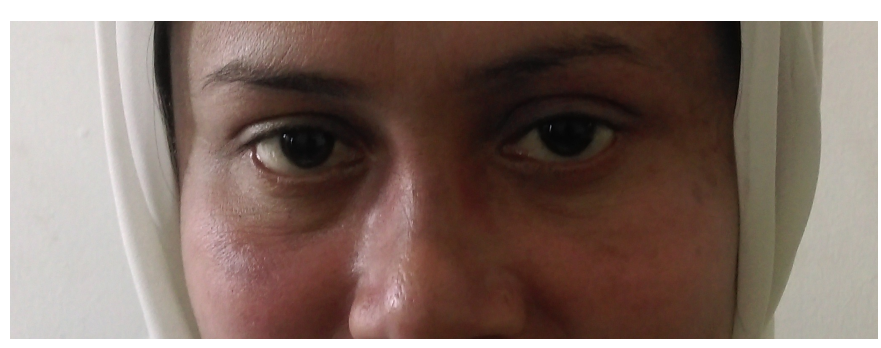

FIGURE 2: Mild PeriorbitalOedema with marked facial Erythema

were consistent with inflammatory myositis. Skin biopsy from upper chest revealed hyperkeratosis, keratotic plugging, mild atrophy of the epidermis, basal liquefaction and lympho histiocytic infiltration at dermo epidermal junction as well as peri vascular region in the upper dermis. Cancer screening including chest X-ray and ultrasonography of whole abdomen were normal. So based on the clinical features and investigations done, the patient was diagnosed as a case of Dermatomyositis.

Her treatment was started with oral prednisolone along with azathioprine, hydroxychloroquine and photo protection with sun-screen. With treatment there was a clear response to treatment with resolution of skin lesions, gradual improvement of her muscular weakness and reducing level of CPK and LDH (780U/L and 417U/L respectively after one month of treatment). She was advised for regular follow up.

EMG findings Summary: Inflammatory myopathy 
MANUSCRIPT CENTRAL

TABLE 1: TA: TibialisAnterior, Q: Quadriceps, GM: Gluteus Medius, Inc: Increment, Sh: Short, F: Full

\begin{tabular}{|c|c|c|c|c|c|c|c|c|c|c|c|c|}
\hline $\begin{array}{l}\text { Muscle/ } \\
\text { Slide }\end{array}$ & $\begin{array}{l}\text { Ins. } \\
\text { Act }\end{array}$ & Fibs & $\begin{array}{l}\text { Pos. } \\
\text { Wave }\end{array}$ & Fasc. & $\begin{array}{l}\text { MYO } \\
\text { Disch }\end{array}$ & $\begin{array}{l}\text { Normal } \\
\text { MUP }\end{array}$ & Poly & $\begin{array}{l}\text { Low } \\
\text { Amp }\end{array}$ & $\begin{array}{l}\text { High } \\
\text { Amp }\end{array}$ & Dur & Rec & $\begin{array}{l}\text { Int. } \\
\text { Patt }\end{array}$ \\
\hline TA L & Inc & +2 & +2 & 0 & 0 & 0 & & +3 & 0 & Sh & $F$ & $\mathrm{~F}$ \\
\hline$Q \mathrm{~L}$ & Inc & +1 & +3 & 0 & 0 & 0 & & +3 & 0 & Sh & $\mathrm{F}$ & $\mathrm{F}$ \\
\hline QR & Inc & +3 & 0 & 0 & 0 & 0 & +++ & +3 & 0 & Sh & $\mathrm{F}$ & $F$ \\
\hline GM L & Inc & +3 & 0 & 0 & 0 & 0 & ++ & +2 & 0 & Sh & $\mathrm{F}$ & $\mathrm{F}$ \\
\hline
\end{tabular}

\section{3 | DISCUSSION:}

Dermatomyositis (DM) is one of the idiopathic inflammatory myopathies. ${ }^{1-3}$ Bohan and Peter ${ }^{4}$ suggested 5 subsets of myositis-DM, PM, myositis with cancer, childhood DM/PM, and myositis overlapping with another collagen vascular disorder. In a subsequent publication, Bohan et $\mathrm{al}^{13}$ noted that cutaneous disease may precede the development of the myopathy; however, it was only recently recognized that another subset of patients with disease that only affects the skin (amyopathic DM [ADM] or DMsine myositis) may occur. ${ }^{14}$ A seventh subset known as inclusion body myositis has been recognized in $1979 .{ }^{15,16}$ Perhaps there is an eighth group in which characteristic cutaneous disease is drug-induced. ${ }^{17}$ Finally, Sontheimer ${ }^{18}$ has proposed that other subsets exist for patients with cutaneous disease including classic DM, ADM, and at least 2 additional subsets known as hypomyopathic DM, when the skin disease is present with subtle muscle disease, evident with studies other than enzymatic analysis, and finally, a subset known as post-myopathic DM when patients with previous classic DM have the myositis resolve, but the skin disease remains active.

$\mathrm{DM}$ is autoimmune in pathogenesis and results from a vasculopathy. Both cell mediated immunity to muscle antigen and immune complex disease may play role in the pathogenesis ${ }^{19}$. Along with symmetrical proximal muscle weakness the characteristic and possibly pathognomonic cutaneous features of DM are the heliotrope rash and Gottron's papules. Other skin manifestations of DM include, erythematous malar rash, confluent macular violaceous erythema overlying the extensor aspect of the upper extremity, $\mathrm{V}$ area of anterior neck and chest, central aspect of the face, peri orbital areas, forehead of the scalp, lateral aspect of the hip and thigh, periungual telangiectasia, poikiloderma, hyperkeratosis or mechanical hands, cuticular over growth, panniculitis, cutaneous vasculitis. The skin lesions of DM are probably photoaggravated. Clinical observations suggest that not only is the skin disease exacerbated by light, but muscle disease may be worsened after sun exposure. ${ }^{20-23}$ Phototesting has however not been able to reliably reproduce the skin lesions; thus, the wavelength of light that is responsible for the clinical manifestations (action spectrum) is not known. Scalp involvement in $\mathrm{DM}$ is relatively common and is manifested by an erythematous to violaceous, psoriasiform dermatitis. ${ }^{24}$ in our case there was focal non scaring alopecia. Nitsche et al first published a case of widespread subcutaneous edema as part of the dermatomyositis syndrome in $1988^{25}$ in contrast to some periorbital oedema noted in our case. The underlying pathogenesis for the subcutaneous edema remains to be elucidated. It has been thought that

increased vascular permeability in the tissues and muscles leads to extensive leakage of fluid into surrounding structures ${ }^{26}$. This implies that subcutaneous edema may be a result of severe inflammation and an indirect indicator of aggressive disease. On the other hand, there may also be a role for an immune complex mediated vasculitis ${ }^{27}$. Recently, evidence has emerged linking the pathogenesis of dermatomyositis to type I interferons. A case report of severe dermatomyositis exacerbated/induced by interferon beta therapy was published in 2008, supported by in vitro evidence of enhanced type 1 interferon signaling in response to interferon beta. ${ }^{28}$ The optimal treatment of dermatomyositis associated remains unclear. The mainstay of therapy involves glucocorticoids, which are thought to act through anti-inflammatory and immunosuppressive effects. $^{25,29}$ However, additional immunosuppres- 
sive agents such as azathioprine, hydroxychloroquine, mycophenolate-Mofetil and methotrexate are often employed as a more aggressive attempt to gain control of disease. IV Ig has also been administered in severe, life threatening cases; eight out of nine patients given IVIg eventually recovered from their illness. ${ }^{26,30,31,32,33}$ Newer biological agents have shown great promise in refractory cases of dermatomyositis. Rituximab has been successfully used in the treatment of refractory dermatomyositis and other inflammatory myopathies. ${ }^{34,35}$

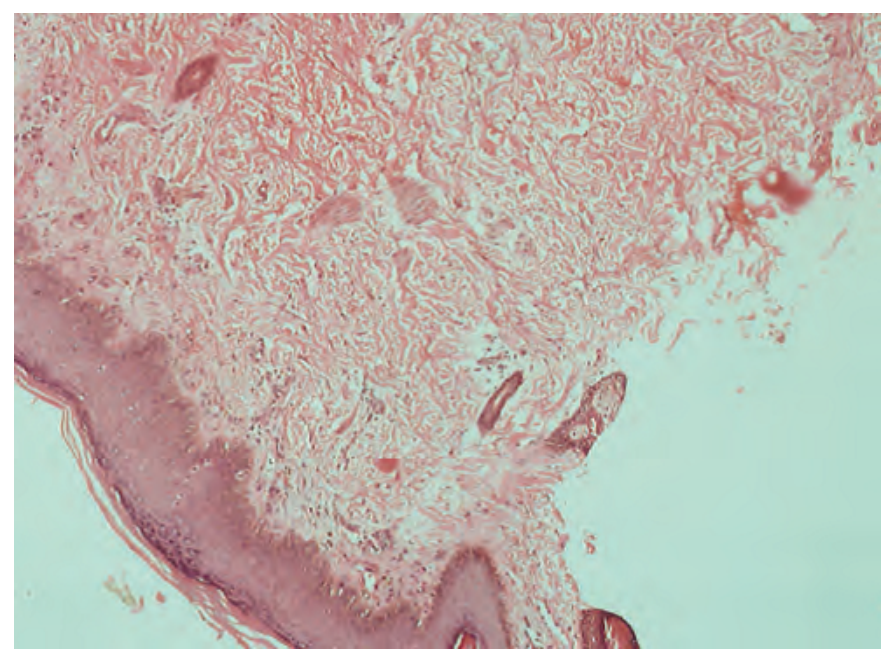

FIGURE 3:

\section{4 | CONCLUSION:}

Dermatomyositis is a condition primarily of skin and muscle, but other systemic features may occur. The pathogenesis of the muscle disease is becoming better understood but the cutaneous disease mechanisms remain enigmatic. Dermatomyositis in adults is associated with malignancy, and, thus, a careful evaluation of each patient should be part of their initial and follow-up assessments. Patients should also be evaluated for the presence of esophageal, pulmonary, and cardiac disease. Corticosteroids, immunosuppressives, biologic agents, and/or immune globulin are effective therapies for the myopathy of $\mathrm{DM}$, whereas the skin disease is best managed with sun protection, topical corticosteroids, antimalarials, methotrexate, and/or immune globulin. The prognosis is good except for patients with malignancy, those with severe weakness, and those with cardiac dysfunction, interstitial lung disease, or the presence of a myositis-specific autoantibody other than Mi-2.

\section{5 | REFERENCE:}

1. Callen JP. Dermatomyositis. Lancet 2000;355:53 $-7$.

2. Plotz PH, Rider LG, Targoff IN, Raben N, O'Hanlon TP, Miller FW. Myositis: immunologic contributions to understanding cause, pathogenesis, and therapy. Ann Intern Med 1995;122:715- 24.

3. Targoff IN. Dermatomyositis and polymyositis. Curr Probl Dermatol

1991;3:131 - 80 .

4. Bohan A, Peter JB. Polymyositis and dermatomyositis. N Engl J Med

1975;292:344 - 7 and 403- 7 [two part article].

5. Kuru S, Inukai A, Liang Y, Doyu M, Takano A, Sobue G. Tumor necrosis factor-a expression in muscles of polymyositis and dermatomyositis. Acta Neuropathol 2000;99:585- 8 .

6. Wanchu A, Khullar M, Sud A, Bambery P. Nitric oxide production is

increased in patient with inflammatory myositis. Nitric Oxide 1999; 3:454- 8 .

7. Shimizu T, Tomita $Y$, Son K, Nishinarita S, Sawada S, Horie T. Elevation of serum soluble tumor necrosis factor receptors in patients with polymyositis and dermatomyositis. Clin Rheumatol 2000;19: 352- 9 .

8. Sugugiura T, Kawaguchi Y, Harigai M, et al. Increased CD40 expression on muscle cells of polymyositis and dermatomyositis: role of CD40CD40 ligand interaction in IL-6, IL-8, IL-5, and monocyte chemoattractant protein-1 production. $\mathrm{J}$ Immunol 2000; 164:6593- 600.

9. Nyberg P, Wikman A-L, Nennesmo I, Lundberg I. Increased expression of interleukin 1a and MHC class I in muscle tissue of patients with chronic, inactive polymyositis and dermatomyositis. J Rheumatol 2000;27:940 - 8 . 


\section{MANUSCRIPT CENTRAL}

10. William D. James, Timothy G. Berger, Dirk M. Eloston,. Andrews's diseases of the skin. 11th edition 2011, 165-168.

11. M.J.D. Goodfield, S.K. Jones and D.J.Veale, the 'Connective Tissue Diseases'. Rook's Textbook of Dermatology.8thedition ,2010;51.120-51.129

12. Brain R Walker, Nicki R Colledge, Stuart H Relston, Ian D Penman. Davidson's Principles and Practice of Medicine. 22 ${ }^{\text {nd }}$ ed. Elsevier limited; 2014. p.1114.

13. Bohan A, Peter JB, Bowman RL, Pearson CM. A computer-assisted analysis of 153 patients with polymyositis and dermatomyositis. Medicine 1977;56:255 - 86.

14. Euwer RL, Sontheimer RD. Amyopathic DM (DM sine'myositis). J Am Acad Dermatol 1991;24:959- 66.

15. Sayers ME, Chou SM, Calabrese LH. Inclusion body myositis: analysis of 32 cases. J Rheumatol 1992;19:1385- 9.

16. Calabrese LH, Chou SM. Inclusion body myositis. Rheum Dis Clin North Am 1994;20:955- 72.

17. Dourmishev AL, Dourshimev LA. Dermatomyositis and drugs. Adv Exp Med Biol 1999;445:187 - 91 .

18. SontheimerRD.Would a new name hasten the acceptance of amyopathic dermatomyositis (dermatomyositis sine myositis) as a distinctive subset within the idiopathic inflammatory dermatomyopathies spectrum of clinical illness? J Am Acad Dermatol 2002;46:626-36.

19. Adriana Maluf Elias Sallum, Maria Helena Bittencurt Kiss, Silvana Sachetti, Maria Bernadate Dutra Resende, Kelly Cristina Moutinho, Mary de Souza Carvalho, Clovis Arthur Almeida Silva, Suely Kazue NagahashiMarie.Juvenile dermattomyositis: clinical, laboratorial, histological, therapeutical and evolution parameters of 35 patients Arq Neuropsiquiatr 2002;60(4): 889-899.

20. Woo TR, Rasmussen J, Callen JP. Recurrent photosensitive dermatitis preceding juvenile dermatomyositis. Pediatr Dermatol 1985;2:207- 12.

21. Callen JP. Photodermatitis in a 6-year-old child. Arthritis Rheum 1993;36:1483- 5.
22. Zuber M, John S, Pfreundschuh M, Gause A. A young woman with a photosensitive pruritic rash on her face and upper trunk. Arthritis Rheum 1996;39:1419- 22.

23. Callen JP. Photosensitivity in collagen vascular diseases. Semin Cutan Med Surg 1999;18:293 -6.

24. Kasteler JS, Callen JP. Scalp involvement in dermatomyositis. Often overlooked or misdiagnosed. JAMA 1994;272:1939 - 41.

25. Nitsche A, San Agustin PG, Amado V. Prina AP, Corsaro G. Trunk and Abdominal wall edema in dermatomyositis. Medicina (B Aires). 1988; 48(3):3312. [PMID: 2977631]

26. Chai Y, Bertorini TE, Li YD, Mitchell C, Guan $\mathrm{H}$. Limb edema and anasarca associated with severe dermatomyositis: report of four cases. Neuromuscul Disord. 2011 Jun;21(6):439-42. [PMID: 21482469]

27. Andonopoulos AP, Gogos CA, Tzanakakis G. Subcutaneous Edema: an unrecognised feature of acute polymyositis. Rheumatol Int. 1993; 13(4):159161. [PMID: 8310209]

28. Somani, AK, Swick A, Cooper K. McCormick TS. Severe Dermatomyositis Triggered by Interferon Beta-1a Therapy and Associated With Enhanced Type I Interferon Signalling. Arch Dermatol. 2008 Oct; 144(10): 1341-1349. [PMID: 18936398]

29. Bohan A, Peter JB, Polymyositis and dermatomyositis (first of two parts). N Engl J Med. 1975 1975 Feb 13;292(7):344-7. [PMID: 1090839]

30. Werner de Castro GR, Appenzeller S, Bértolo MB, Costallat LT. Acute dermatomyositis with subcutaneous generalized edema. Clinical Rheumatology, 2006 Nov, 25(6):898-900. [PMID: 16308667]

31. Lee KH, Lim SR, Kim YJ, Lee KJ, Myung DS, Jeong HC, Yoon W, Lee SS, Park YW. Acute dermatomyositis associated with generalized subcutaneous edema. Rheumatol Int, 2008 Jun; 28(8) :797800. [PMID: 18193426]

32. Haroon M, Eltahir A, Harney S. Generalized subcutaneous edema as a rare manifestation of dermatomyositis: clinical lesson from a rare feature. J Clin Rheumatol. 2011 April;17(3):135-7. [PMID: 21441819] 


\section{A CASE OF DERMATOMYOSITIS: DIAGNOSTIC CHALLENGE IN LOW RESOURCE SETTINGS}

33. Jung KD, Kim PS, Park HY, Kim CR, Byun JY, Lee DY, Lee JH, Yang JM, Lee ES. Dermatomyositis associated with generalized subcutaneous edema and Evans syndrome. J Am Acad Dermatol. 2012 Jan ;66(1):144-7. [PMID: 22030016]

34. Noss EH, Hausner-Sypek DL, Weinblatt ME, Rituximab as therapy for refractory polymyositis and dermatomyositis. J Rheumatol. 2006 May; 33:10211026. [PMID: 16541475]

35. Rios Fernandez R, Callejas Rubio JL, Sanchez Cano D, Sáez Moreno JA, Ortego Centeno N. Ritux- imab in the treatment of dermatomyositis and other inflammatory myopathies. A report of 4 cases and review of the literature. Clin Exp Rheumatol. 2009 Nov-Dec; 27(6):1009-16. [PMID: 20149324]

How to cite this article: Gomes R.R., Khan D.S.B. A Case of Dermatomyositis: Diagnostic Challenge in Low Resource Settings. Journal of Medical Care Research and Review. 2020;395-400. https://doi. org/10.15520/mcrr.v3i7.119 